\title{
Examination of the temperature related structural defects of InGaN/GaN solar cells
}

\author{
İlknur Kars Durukan ${ }^{\mathrm{a}, *}$, Özlem Bayal ${ }^{\mathrm{b}}$, Gürkan Kurtuluş ${ }^{\mathrm{b}}$, Yunus Baş ${ }^{\mathrm{c}}$, Ali Gültekin ${ }^{\mathrm{b}}$, \\ Mustafa Kemal Öztürk ${ }^{\mathrm{b}, \mathrm{d}}$, Süleyman Çörekçi ${ }^{\mathrm{e}}$, Mehmet Tamer ${ }^{\mathrm{b}, \mathrm{g}}$, Süleyman Özçelik ${ }^{\mathrm{b}, \mathrm{d}}$, \\ Ekmel Özbay ${ }^{\mathrm{f}}$
}

${ }^{a}$ Life Sciences Research and Application Center, Gazi University, Ankara, Turkey

${ }^{\mathrm{b}}$ Department of Physics, Faculty of Sciences, Gazi University, Ankara, Turkey

${ }^{\mathrm{c}}$ National Boron Research Institute, 06520 Ankara, Turkey

${ }^{\mathrm{d}}$ Photonics Research Center, Gazi University, 06500 Ankara, Turkey

${ }^{\mathrm{e}}$ Energy Systems Engineering Department, Faculty of Technology, Krrklareli University, Kirklareli, Turkey

${ }^{\mathrm{f}}$ Department of Physics, Bilkent University, 06800 Bilkent, Ankara, Turkey

${ }^{\mathrm{g}}$ Department of Physics, Zirve University, Gaziantep, Turkey

\section{A R T I C L E I N F O}

\section{Article history:}

Received 15 June 2015

Accepted 28 July 2015

Available online 30 July 2015

\section{Keywords:}

InGaN

MOCVD

Annealing

XRD

AFM

\begin{abstract}
A B S T R A C T
In this study the effects of the annealing temperature on the InGaN/GaN solar cells with different In-contents grown on sapphire substrate by the Metal Organic Chemical Vapor Deposition (MOCVD) are analyzed by High Resolution X-ray Diffraction (HRXRD) and an Atomic Force Microscope (AFM). The plane angles, mosaic crystal sizes, mixed stress, dislocation intensities of the structure of the GaN and InGaN layers are determined. According to the test results, there are no general characteristic trends observed due to temperature at both structures. There are fluctuating failures determined at both structures as of $350^{\circ} \mathrm{C}$. The defect density increased on the GaN layer starting from $350^{\circ} \mathrm{C}$ and reaching above $400{ }^{\circ} \mathrm{C}$. A similar trend is observed on the InGaN layer, too.
\end{abstract}

(c) 2015 Elsevier Ltd. All rights reserved.

\section{Introduction}

Today's rapid development of the industry converts us to being more dependant on energy. Traditional energy sources like coal and petrol are both limited and constitute a serious threat for living organisms and environment. One of the most promising methods to fight versus these problems is solar energy. Solar energy is a much greater source of energy than fossil based energy sources and other renewable energy sources [1]. Photovoltaics are systems which directly convert sunlight into electrical energy. This process is rather reliable, easy, cost efficient and environment friendly. Therefore high efficient solar cells are very important and one of the most worked on issues during the last ten years in the field of physics [2,3]. The development of solar cells with a high performance by using $\operatorname{In}_{x} \mathrm{Ga}_{1-x} \mathrm{~N}$ is a very important development compared with solar cells made of Si and III-V materials [1,4].

The energy maintenance efficiency of photovoltaic materials obtained by utilizing traditional III-V compound semi-conductors is above 40\% [4]. The expansion of the band range of InN by generating compounds with III-nitride alloys has created broader working conditions and prepared the environment for new applications [5,6]. III-nitride properties are

\footnotetext{
* Corresponding author.

E-mail address: ilknurdurukan@gazi.edu.tr (i. Kars Durukan).
} 
widely used for solar cells because of their wide band range, low efficient carrier load, high mobility, high absorption coefficiency, high heat conductivity and high temperature resistance [7-11]. The III-N technology has a suitable structure for producing high quality devices and is more resistant versus challenging operating conditions compared with Si solar cells [4]. Many different groups have worked on the structures of InGaN solar cells since 2003, although these studies yielded in 2007 as the desired crystal structure and high efficiency were unable to be reached. Furthermore, the growing parameters, surface dynamics and lattice structures are of significant importance for the development of nitride based optoelectronic and microelectronic devices. The temperature has a critical importance due to its effect on the lattice structures and the modification of the band range [12]. However, the studies performed with regards to the effect of temperature on the device performance are insufficient. In order to contribute to the literature, InGaN/GaN structures grown on c-oriented sapphire substrate by the Metal Organic Chemical Vapor Deposition (MOCVD) method are annealed between 300 and $500{ }^{\circ} \mathrm{C}$ at stages of $50{ }^{\circ} \mathrm{C}$. The effect of these annealings on the solar cells and subsequently on the device performance are examined comprehensively. The surface morphology and layers of the samples are examined. The edge and screw type dislocation densities are calculated. The modification of the mosaic structure parameters and dislocation intensities due to the temperature are determined.

\section{Preparation of the samples}

The In-graded (sample A) and In-ungraded (sample B) InGaN/GaN solar cell structure are grown on c-oriented sapphire substrate using the MOCVD method. The epitaxial film is annealed for $10 \mathrm{~min}$ at $1.100{ }^{\circ} \mathrm{C}$ under $\mathrm{H}_{2}$ gas prior to the growing in order to eliminate the contaminations on the surface. The epitaxial growing process after the decontamination process is initiated by growing the GaN nucleation layer at $575^{\circ} \mathrm{C}[13,14]$. The TMGa flow speed is settled $10 \mathrm{sccm}$, the $\mathrm{NH}_{3}$ flow speed as $1.500 \mathrm{sccm}$ and the growing pressure as $200 \mathrm{mbar}$ during the growing process. The thickness of this nucleation layer is $10 \mathrm{~nm}$. After the completion of the nucleus layer the GaN buffer layer is grown on it at $1.070{ }^{\circ} \mathrm{C}$. The growth of the buffer layer is provided by setting the TMGa flow rate to $15 \mathrm{sccm}$, the $\mathrm{NH}_{3}$ flow rate to $1.800 \mathrm{sccm}$ and stabilizing the growing pressure at 200 mbar. The thickness of the GaN buffer layer is $1.6 \mu \mathrm{m}$. The growing process is continued by opening the SiH $\mathrm{H}_{4}$ source and an $n$ type GaN layer is obtained by the aid of the $\mathrm{SiH}_{4}$ source. The $\mathrm{SiH}_{4}$ source has diluting properties during the MOCVD process. The flow rate of the $\mathrm{SiH}_{4}$ source is $10 \mathrm{sccm}$. The $\operatorname{In}_{x} \mathrm{Ga}_{1-x} \mathrm{~N}$ active layers in sample A and B are grown at temperature of $745-760{ }^{\circ} \mathrm{C}$ and an In flow rate of $75 \mathrm{sccm}$. While the InGaN layer thicknesses of sample A is $25 \mathrm{~nm}$ (graded) and $200 \mathrm{~nm}$ (graded), the thickness of the InGaN layer (ungraded) is $220 \mathrm{~nm}$. The active layers are grown between n-type GaN and p-type InGaN contact layers of $1.9 \mu \mathrm{m}$.

The $\mathrm{p}^{+}$InGaN layer is grown by using a Mg doping source. The flow speed of this source is also 35 sccm. During the growth of the InGaN layers are the sources, which were open during the growth and the other layers, closed. The Mg flow rate is settled as $40 \mathrm{sccm}$ in order to perform a higher doping. Samples A and B are annealed between 300 and $500{ }^{\circ} \mathrm{C}$ at stages of $50^{\circ} \mathrm{C}$ after the growing process. The structure was shown in Fig. 1.

The crystallinity and mosaic failure structure of the films is analyzed by a Cu sourced D8-Advance X-ray diffraction $(\lambda=1.5406 \AA$ A). The AFM surface characterization is performed with an Omicron VT AFM/STM device.

\section{Results and discussion}

\subsection{XRD analysis}

Fig. 2 indicates the $\omega-2 \theta$ XRD scans of sample A and B after thermal annealing. Fluctuations of the peak positions of both the InGaN and GaN are observed. It is thought that this is due to the strain of the micro structure of the crystal. It is seen that there was both pressure and strain on the structure. Furthermore, it can be concluded from these strain values that there is

\begin{tabular}{|c|}
\hline p-InGaNlayer $\mathrm{t} \sim 50 \mathrm{~nm}$ \\
\hline $\mathrm{p}$ - InGaNlayer $\mathrm{t} \sim 50 \mathrm{~nm}$ \\
\hline $\begin{array}{l}\text { Graded or Ungra ded InGaN Layer t } ~ 25 \mathrm{~nm} \\
\left(745-760^{\circ} \mathrm{C}\right) 70 \text { sscm }\end{array}$ \\
\hline InGaN Laver $\mathrm{t} \sim 200 \mathrm{~nm}$ sscm $\left(745-760^{\circ} \mathrm{C}\right) 75 \mathrm{sscm}$ \\
\hline N-GaN Layer (6) $\mathrm{t} \sim 12 \mu \mathrm{m}$ ss $\mathrm{cm}$ \\
\hline un-GaN Layer (5)t $1.5 \mu \mathrm{m}$ \\
\hline un-GaN Layer (4) $t \sim 2 \min$ \\
\hline un-GaN Layer (3) $\mathrm{t} \sim 1 \mathrm{~min}$ \\
\hline un-GaN Layer (2) $t \sim 2 \mathrm{~min}$ \\
\hline un-GaN Layer (1) $t \sim 10$ sec \\
\hline LT GaN nucleation layer (2.45 min) \\
\hline $\mathrm{Al}_{2} \mathrm{O}_{3}$ (c-oriented) (substrate) \\
\hline
\end{tabular}

Fig. 1. The InGaN layered solar cell structure has a thickness of $t$ in the figure. Two sample structures with InGaN graded (sample A) and ungraded (sample B) layers of $25 \mathrm{~nm}$. 

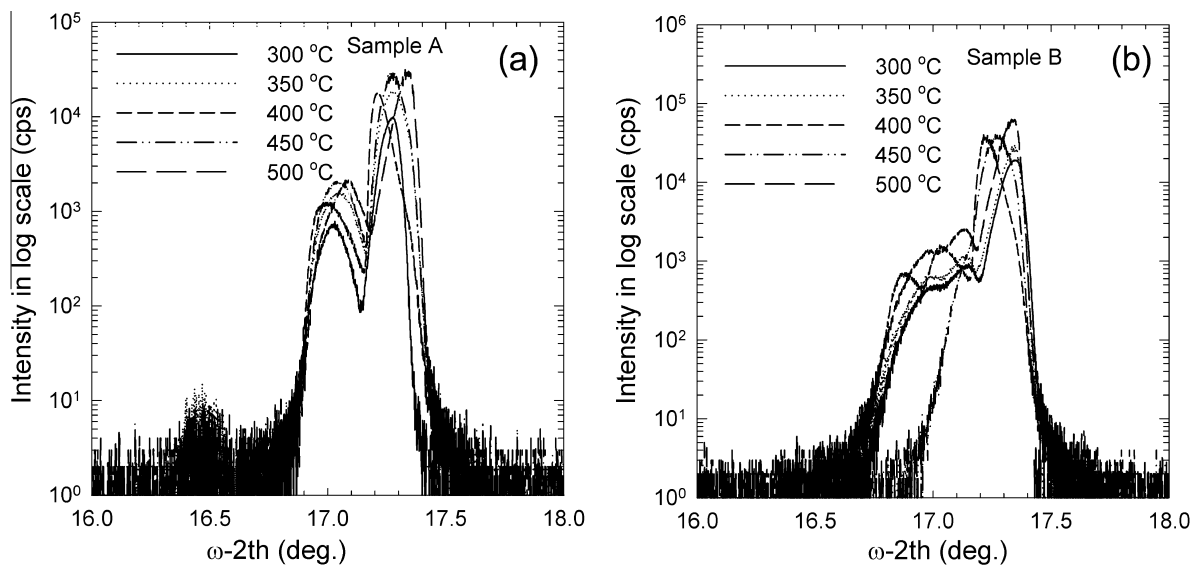

Fig. 2. $\omega-2 \theta$ scans at $300-500{ }^{\circ} \mathrm{C}$, (a) sample $\mathrm{A}$, (b) sample $\mathrm{B}$.

stress on the low sized structure. Also, temperature dependant structural instabilities are observed on the ungraded In sample. That is because while GaN was subjected to a micro-strain, crystal deformations at a high rate along with In deformation was observed on the InGaN sample.

The FWHM values of the peaks obtained by the high resolution XRD scan of the crystal plane of GaN and InGaN layers (002) for sample A and B depending on the annealing temperature are indicated in Fig. 3. The FWHM values are determined with the EVA program by data of the peaks in the Gaussian and Lourence type functions.

Meanwhile examining Fig. 3a, a stable FWHM is observed until $350{ }^{\circ} \mathrm{C}$, increasing FWHM values at $400{ }^{\circ} \mathrm{C}$, decreasing values at $450{ }^{\circ} \mathrm{C}$ and definitely increasing values at $500^{\circ} \mathrm{C}$ are determined. When examining Fig. $3 \mathrm{~b}$, it is to be seen that the InGaN (002) layer presented an increasing and decreasing behavior for sample A, an increase until $400{ }^{\circ} \mathrm{C}$ and that it continued later by decreasing.

High density GaN epitaxial layers are frequently defined by mosaic models [15]. As to be seen in Fig. 4, the mosaic layer consists of a single crystal block with a lateral and vertical mosaic crystal dimension. The blocks except the twist plane are
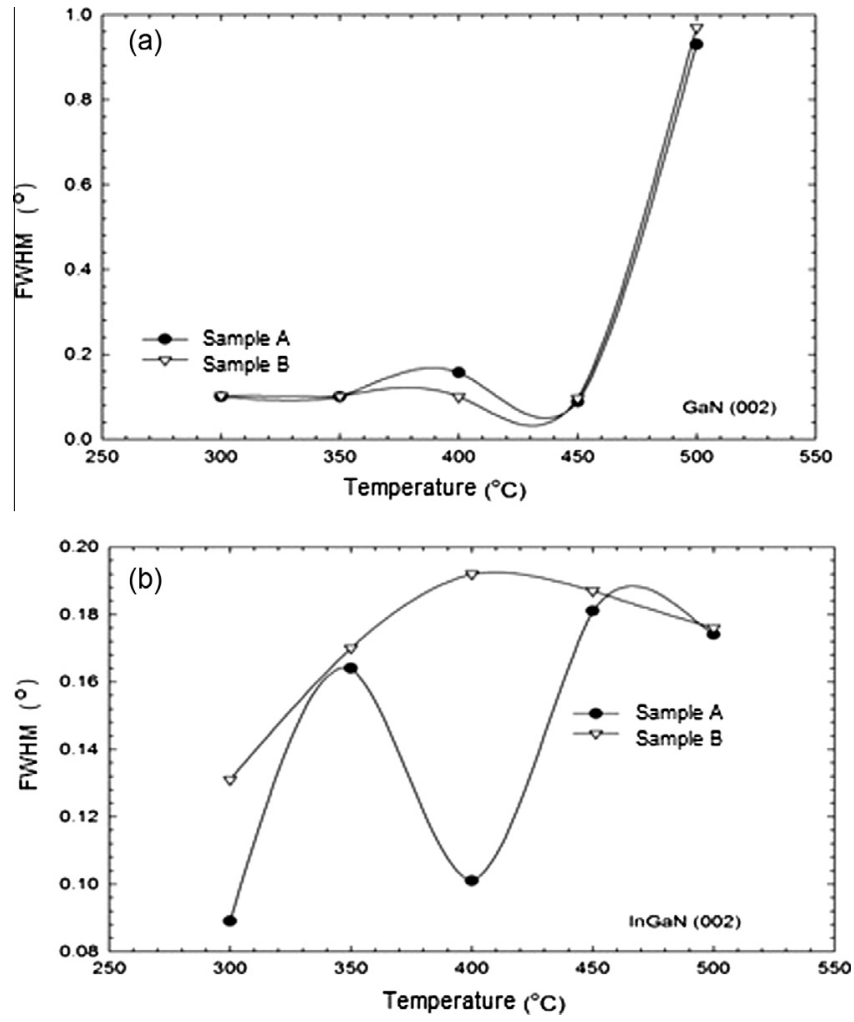

Fig. 3. The FWHM values of the peaks obtained by the high resolution XRD scan of the crystal plane of the GaN and InGaN layers (002) for sample A and B depending on the annealing temperature. 


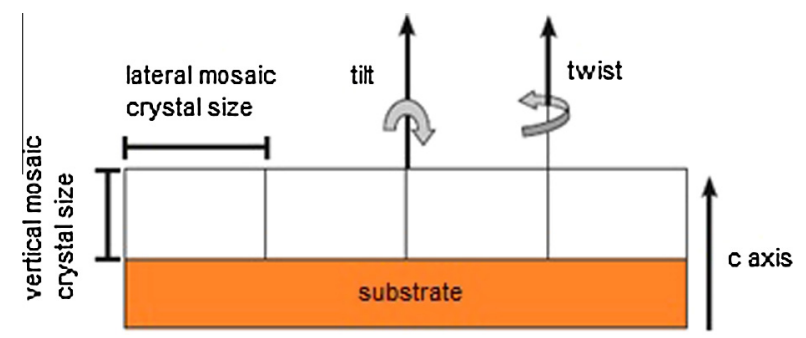

Fig. 4. Schematic display of the mosaic model.

perpendicular to the surface normal and named as tilt. Twist is the rotation around the surface normal [15]. The XRD peaks for the mosaic GaN layer expand due to properties like twisting, tilting, limited crystal dimension and microstrain [16]. Symmetric $\omega$ scans and azimuth $\phi$ scans are analyzed in order to evaluate the mosaic structure of the GaN layer.

On the symmetric and asymmetric scans are the frequently coming and going of wave vectors inside the dispersion plane containing the same $z$ or polar axis. The symmetric diffraction geometry cause the expansion of the perpendicular to the pole axis rotation curves for the lateral dimensions and tilt angles of the mosaic blocks. The contribution of both effects results in the linear dependency on the expansion of the reflection level and this is used in order to differenciate between both contributions. In addition to this purpose, a Williamson-Hall $(\mathrm{W}-\mathrm{H})$ plot $[17,18]$ can be used, which is a linear curve drawn by utilizing the FWHMs of the twist curves as a function of the reflection levels. The contrary graphic of the FMHM $(\sin \theta) / \lambda$ function versus the $(\sin \theta) / \lambda$ function is drawn. FWHM is the total width of the measured profile. $\lambda$ and $\theta$ are the wave lengths and arrival angle of the X-ray, respectively. The plane tilt angle is determined from the opposite of the section point of the lateral mosaic dimension axis when being obtained from the tilt of the linear dependency of the $\mathrm{W}-\mathrm{H}$ curve. The obtained tilt and the lateral mosaic dimensions are indicated in Fig. 5.

The radial scan ( $\omega-2 \theta$ scan) directions of symmetric reflections (002), (004) and (006) result in the expansion of the vertical crystal mosaic dimension along the $c$ axis and the heterogeneous strain Bragg reflections. These two parameters $L_{\perp}$ and $\varepsilon_{\perp}$ are derived from the Williamson-Hall graphic. $\beta_{\omega-2 \theta}(\cos \theta) / \lambda$ is drawn versus $(\sin \theta) / \lambda$ in the Williamson-Hall graphic and quitted to the straight. The vertical mosaic crystal dimension $L_{\perp}$ is calculated by utilizing $y_{o}$ obtained by the aid of the point sectioning the $y$ axis, the $L=0.9 /\left(2 y_{o}\right)$ relation and the tilt of the heterogeneous strain $\varepsilon_{\perp}$, as $4 \varepsilon_{\perp}$ [19].
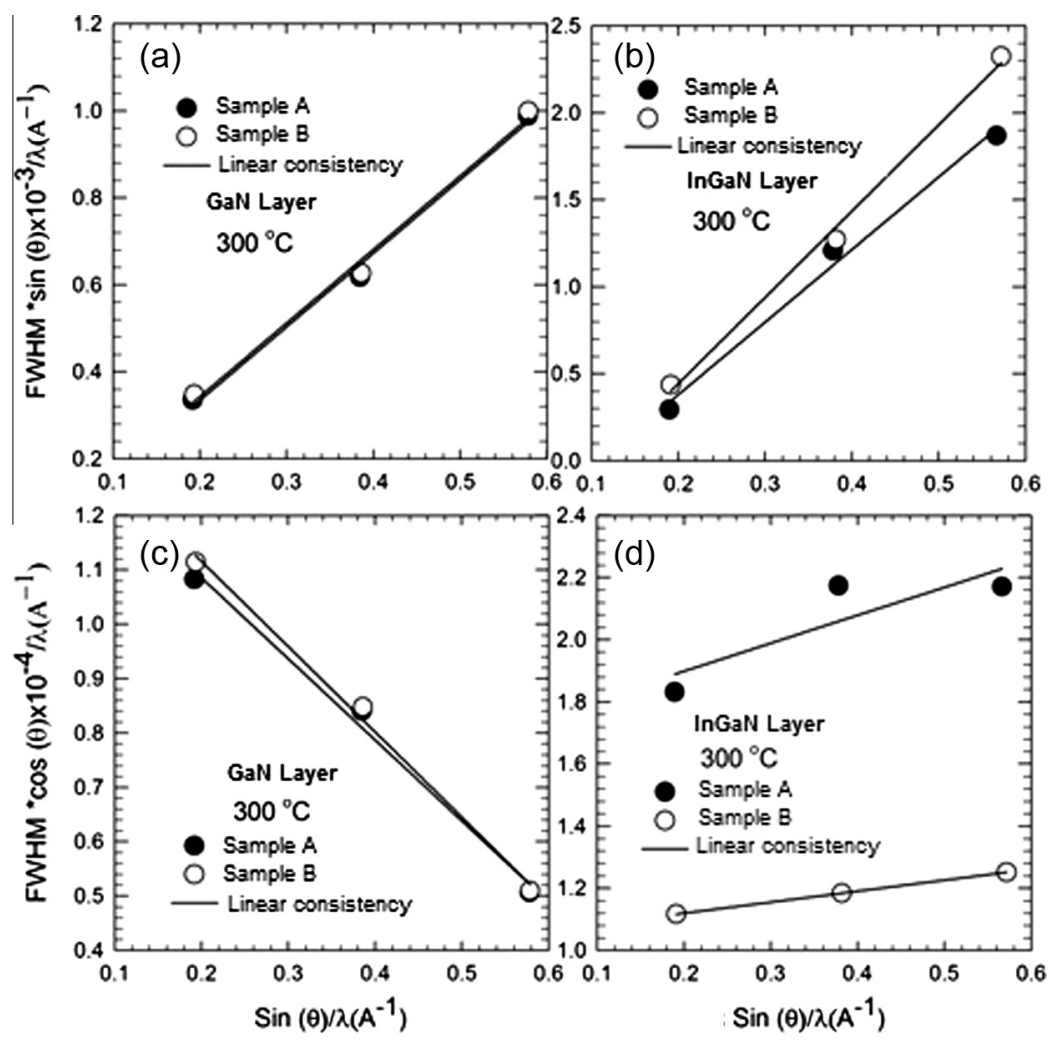

Fig. 5. Temperature dependant Williamson-Hall curves for the GaN and InGaN layers of samples A and B, (a) for GaN $300{ }^{\circ} \mathrm{C}$, (b) for InGaN $300{ }^{\circ} \mathrm{C}$, (c) for GaN $300^{\circ} \mathrm{C}$, (d) for InGaN $300^{\circ} \mathrm{C}$. 
The hexagonal structured GaN shows high defect density when accumulated on different substrates like $\mathrm{Al}_{2} \mathrm{O}_{3}$, $\mathrm{SiC}$ and $\mathrm{Si}$ due to lattice inconsistency. These failures are dislocations and the main types of them [20,21]. Pure edge type dislocations by Burgers vectors are determined by Eq. (1);

$$
b=1 / 3\langle 11 \overline{2} 0\rangle(\langle a\rangle)
$$

Screw type dislocations by Eq. (2);

$$
b=\langle 0001\rangle(\langle c\rangle)
$$

And mixed dislocations by Eq. (3);

$$
b=1 / 3\langle 11 \overline{2} 3\rangle(\langle c+a\rangle)
$$

The edge and screw type dislocation intensities are calculated in this study by the equations below [22].

$$
D_{\text {screw }}=\beta^{2} / 9 b_{\text {screw }}^{2} \quad D_{\text {edge }}=\beta_{(10.2)}^{2} / 9 b_{\text {edge }}^{2}
$$

The FWHM calculated by the XRD twist curves are indicated with $\beta$, determination of the crystalline status of the sample and $b$ is the Burgers vector length. For $\mathrm{GaN}$ is $b_{\text {screw }}=0.5185 \mathrm{~nm}, b_{\text {edge }}=0.3189 \mathrm{~nm}$. The total dislocation density of InGaN multiple layers and GaN layers are calculated by Eq. (5).

$$
D_{\text {total dislocation }}=D_{\text {screw }}+D_{\text {edge }}
$$

The scan of the symmetric reflection in radial directions, heterogeneous strain along the vertical crystal dimension and $c$ axis such to be perpendicular to the lower layer surface results in the expansion of the Bragg reflections. In the symmetric and asymmetric scans are the coming and going wave vectors inside the same $z$ axis containing the dispersion plane. The lateral crystal dimension and the tilt of the mosaic blocks obtained by the symmetric diffraction result in the expansion of the HRXRD twist peak curves of the planes vertical to the $z$ axis [23]. The contribution of these two effects results in a linear dependency on the expansion of the reflection plane and this situation is used in order to differenciate the effect of each one. For this purpose, the Williamson-Hall $(\mathrm{W}-\mathrm{H})$ drawing, which is the linear curve drawn by utilizing the FWHMs of the twist curves as the function of the reflection levels, can be used and is obtained by drawing the FWHM $(\sin \theta) / \lambda$ function graphic contrary to the $(\sin \theta) / \lambda$ function $[24,25]$. Fig. 5 indicates the Williamson-Hall curves of the InGaN and GaN layers respectively. Though being drawn for all temperature, the graphics for $300^{\circ} \mathrm{C}$ are shown in the figure.

While the values are measured in steps, $50{ }^{\circ} \mathrm{C}$ in Fig. 6a sample A lays out a decrease after $350{ }^{\circ} \mathrm{C}$, and sample B had a minimum value at $350^{\circ} \mathrm{C}$. Sample $\mathrm{A}$ is at a minimal level of $400^{\circ} \mathrm{C}$. On the other hand, while sample A once again lays out a decrease after $450{ }^{\circ} \mathrm{C}$, it is observed that sample B provided an increase and reached the maximal level of $500{ }^{\circ} \mathrm{C}$. While sample B provided an oscillation at low magnitude along with the increasing temperature at $10^{3}$ level, the GaN layer of sample A has an oscillation at a broad magnitude. The tilt angle of sample A depends on the growing conditions. That is because the high defect density of the buffer layer effects the MQW structures. Buffer layers like GaN and AlN are grown as mosaic layers and are characterized by their tilt and twist angles. The pit and score failures of these structures are related to these angles and significantly affect the performance [26].

The values in Fig. $6 \mathrm{~b}$ for the InGaN layer at temperature between $300{ }^{\circ} \mathrm{C}$ and $500{ }^{\circ} \mathrm{C}$ sample $\mathrm{A}$ has the maximal value of around $400{ }^{\circ} \mathrm{C}$, and sample B having a minimal value. Both samples A and B lay out a broad oscillation after $350^{\circ} \mathrm{C}$ at $10^{-3}$ level. Here the GaN layer might have reflected its particular score failures on the InGaN layer. That is why the InGaN layer shows an oscillation at sample B, too. It is seen that samples A and B had opposite oscillation values. While sample A's GaN layer has a minimal value at $400^{\circ} \mathrm{C}$, it has a maximal value for the InGaN layer.

As seen in Fig. 7a that sample A and sample B showed a parallel behavior at the lateral mosaic crystal values measured at the GaN layer in scan rate of $50^{\circ} \mathrm{C}$. While sample A provided a broad oscillation at the beginning, it shows a low lateral mosaic dimension change after $400^{\circ} \mathrm{C}$. However, the ungraded structure shows fluctuations at the $10^{-4}$ level.

While the lateral mosaic crystal values measured at temperature of $300^{\circ} \mathrm{C}$ and $500{ }^{\circ} \mathrm{C}$ in Fig. $7 \mathrm{~b}$ shows minimal changes for sample A and a great change for sample B. When the GaN mosaic dimension in sample A decrease and become, the mosaic dimensions of the InGaN layer change at lower levels due to the higher reflection of failures. GaN in sample B, which has low mosaic dimensions, and InGaN again at the same level show a stable change at the beginning until $400{ }^{\circ} \mathrm{C}$ is reached. Following $400{ }^{\circ} \mathrm{C}$ the mosaic structures tend to change to an increasingly perfect structure.

While the values measured on the GaN layer in Fig. 8 a sample A and sample B constituted a stable situation until $400{ }^{\circ} \mathrm{C}$ at the low crystal dimension, sample A shows that after $400^{\circ} \mathrm{C}$ an increasing behavior with high magnitude occurs. A decrease is seen on both structures following temperature values over $450^{\circ} \mathrm{C}$.

Meanwhile being very different at the InGaN layer and the GaN layer, the values measured on the second InGaN layer in steps of $50{ }^{\circ} \mathrm{C}$ in Fig. $8 \mathrm{~b}$, sample B shows an increasing behavior until $400{ }^{\circ} \mathrm{C}$ and then a decreasing behavior, whereas in sample A a stable situation is observed after $400^{\circ} \mathrm{C}$.

For the measured heterogenous(mixed) strain values versus temperature values at the GaN layer, it is seen in Fig. 9 that sample A showed a lattice strained behavior until $400{ }^{\circ} \mathrm{C}$, tending to decrease after $400{ }^{\circ} \mathrm{C}$ and then to increase. The heterogenous strain in sample B shows the same behavior as in sample A with a higher lattice dominant strain value. 

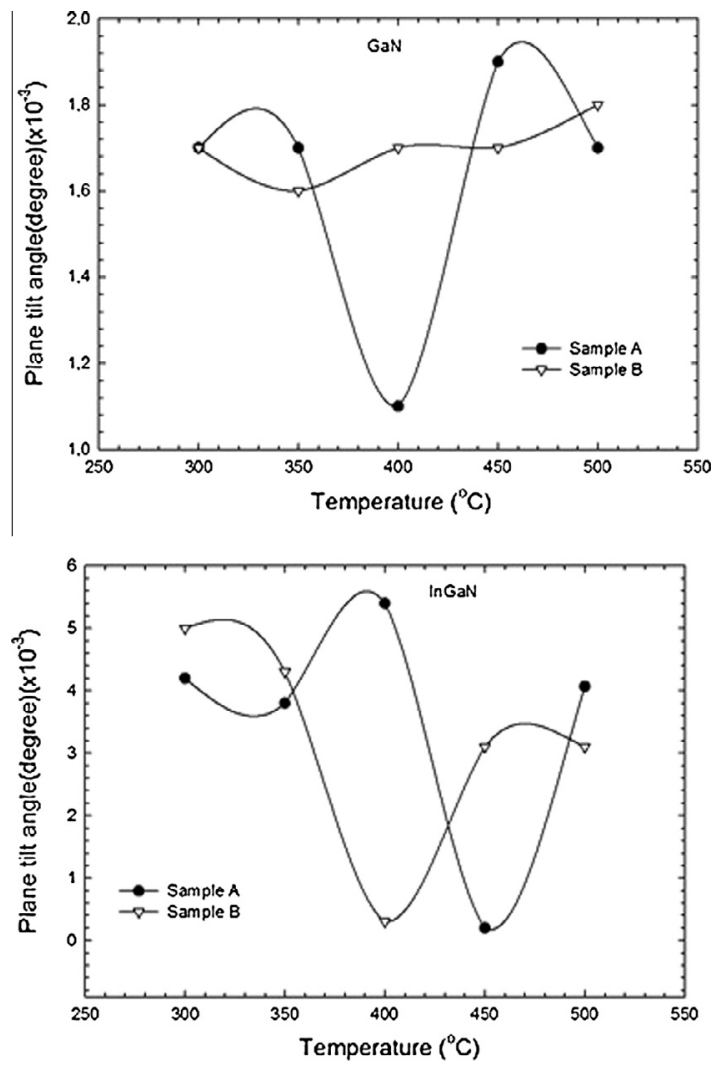

Fig. 6. Temperature dependant plane angle (a) GaN, (b) InGaN.
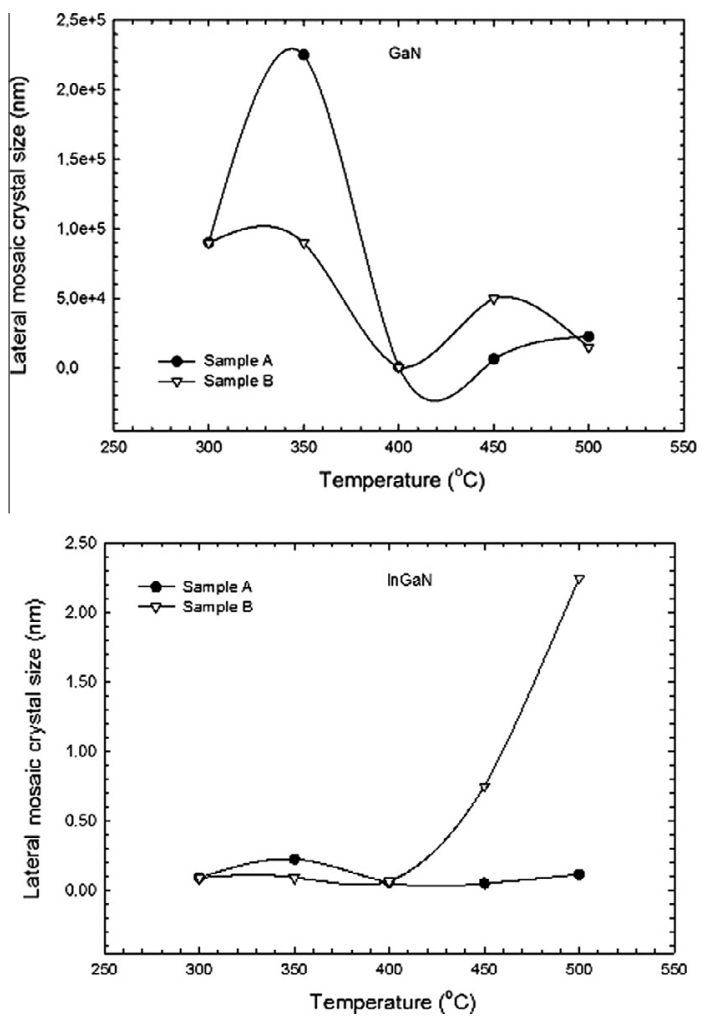

Fig. 7. Temperature dependant lateral mosaic dimension (a) GaN, (b) InGaN. 

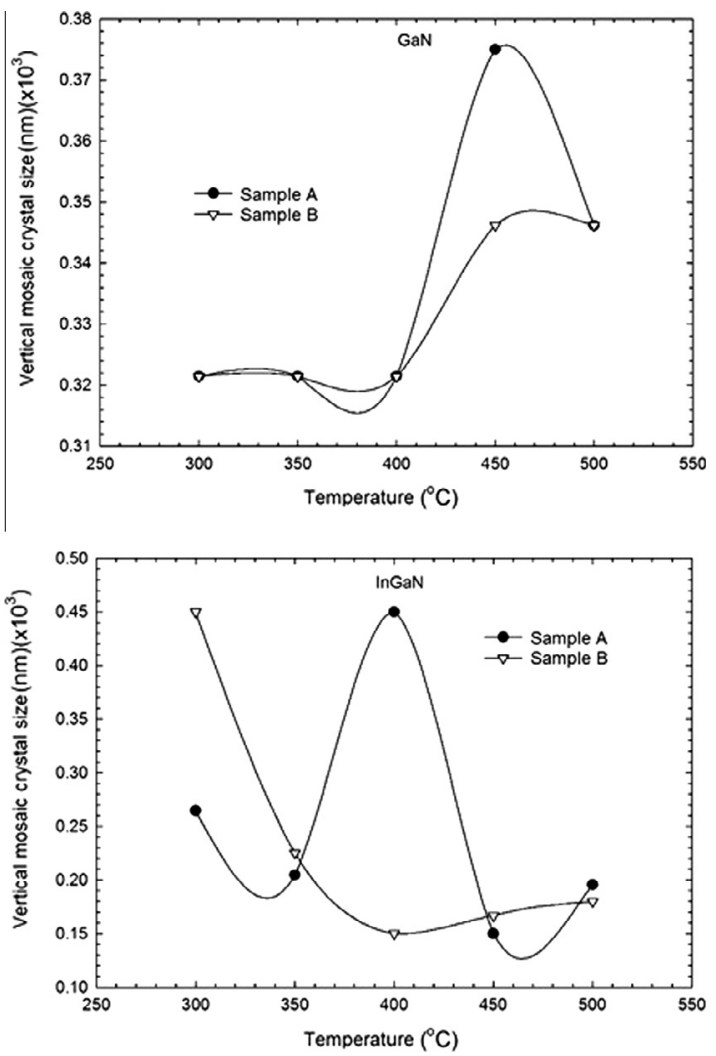

Fig. 8. Temperature dependant vertical mosaic dimension(tilt) of (a) GaN, (b) InGaN.
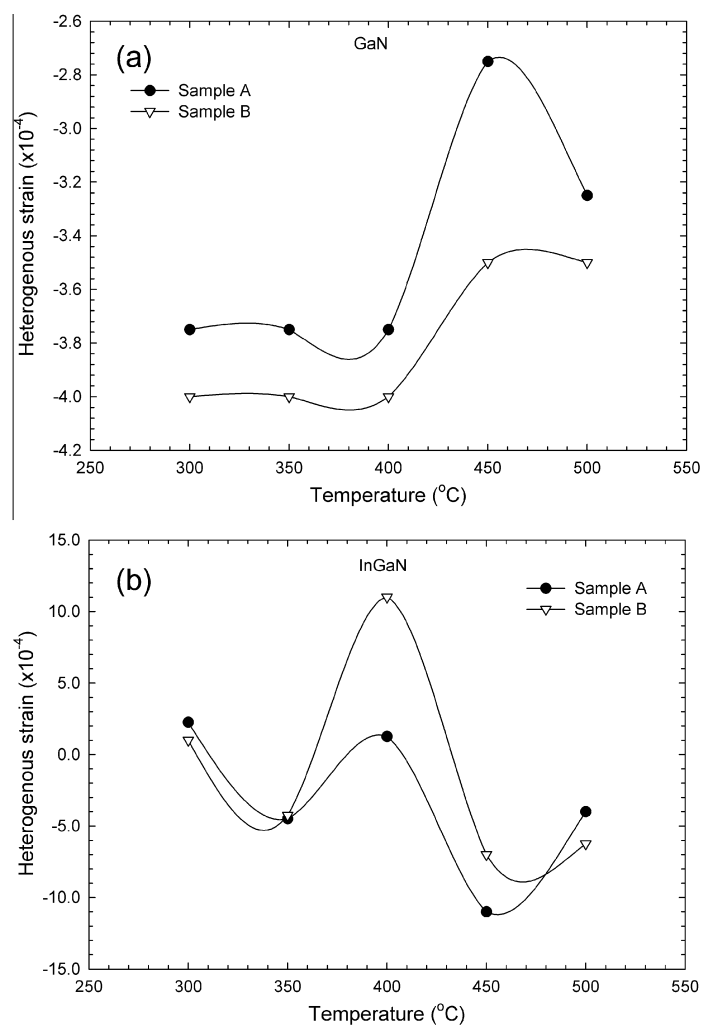

Fig. 9. Temperature dependant heterogenous strain (a) GaN, (b) InGaN. 

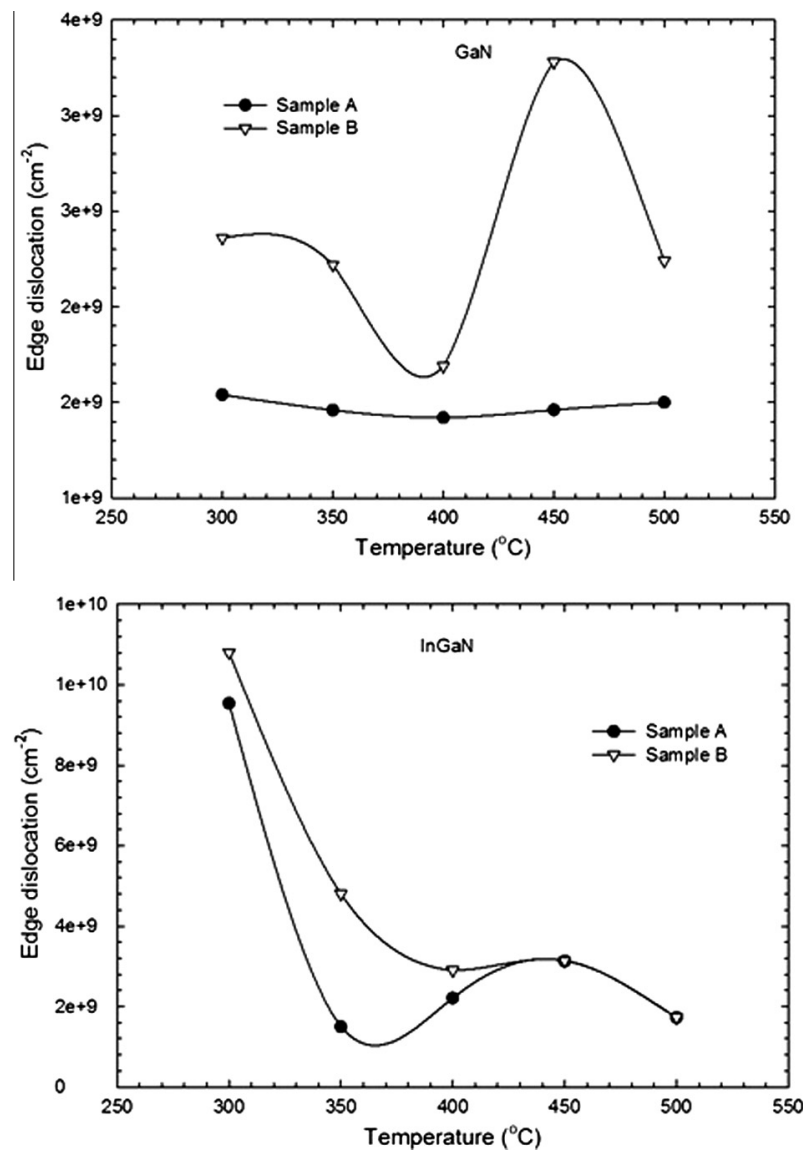

Fig. 10. Temperature dependant edge type dislocation density (a) GaN, (b) InGaN.

Both structures reach $400{ }^{\circ} \mathrm{C}$ the maximal value of the heterogenous strain values in Fig. $9 \mathrm{~b}$ for the InGaN layer. While the lattice dominating strain plays an important role on the InGaN layer of sample A, it has a lattice stressing strain of about $400{ }^{\circ} \mathrm{C}$ for sample B. Both structures present a broad oscillation due to the increasing annealing temperature. Both samples $\mathrm{A}$ and $\mathrm{B}$ provide an increasing value once the temperature exceeds $450^{\circ} \mathrm{C}$.

Fig. 10a indicated a lower dislocation density for the GaN layer of sample A compared to sample B at the edge dislocations by the changing temperature according to the measured values. However, it results in oscillations of a broader magnitude beginning at $350^{\circ} \mathrm{C}$, increasing after $400^{\circ} \mathrm{C}$ and reaching the maximal value of $450{ }^{\circ} \mathrm{C}$ for sample $\mathrm{B}$.

The same behavior of sample A and sample B attracts the attention of Fig. 10b and it is seen that there is a lower dislocation density for sample A. Both structures reached the maximal value of $450{ }^{\circ} \mathrm{C}$ and tended later to decrease. The dislocation intensities showed the same behavior at high temperature.

As to be seen in Fig. $11 \mathrm{a}$, while the screw dislocation density of the GaN layer of sample A tended to increase after $350^{\circ} \mathrm{C}$, it came to a peak at $400{ }^{\circ} \mathrm{C}$ and then tended to decrease. It increased again after $450{ }^{\circ} \mathrm{C}$. Sample B remained stable at the $10^{+8}$ level.

It is shown in Fig. 11b that while the screw dislocation values of the InGaN layer measured at temperature of $300{ }^{\circ} \mathrm{C}$ and $500{ }^{\circ} \mathrm{C}$ it showed a stable situation of the dislocation density at low levels for sample A. For sample B it is seen that it decreased at $350^{\circ} \mathrm{C}$ from $10^{+10}$ level until $10^{+8}$ level and than remained stable.

\subsection{AFM analysis}

Fig. 12 shows the AFM images recorded as a result of the scans performed on the InGaN surfaces of sample A and B after the annealing process at temperature of $300^{\circ} \mathrm{C}$ and $500{ }^{\circ} \mathrm{C}$. It is clearly seen from the images that significant changes occured at the surface structures of the films after thermal processing. Both samples have the lowest roughness within themselves after being annealed at $300^{\circ} \mathrm{C}$. The reason for this change is with high possibility the surface diffusion. The surface of the samples became increasingly rougher depending on the temperature after being annealed at higher temperature $\left(500{ }^{\circ} \mathrm{C}\right)$ and the surface morphologies of both samples have changed dramatically. This behavior can be attributed to the increase of the temperature dependant Indium segregation. The typical terrace structure on III-nitride surfaces resembling surface 

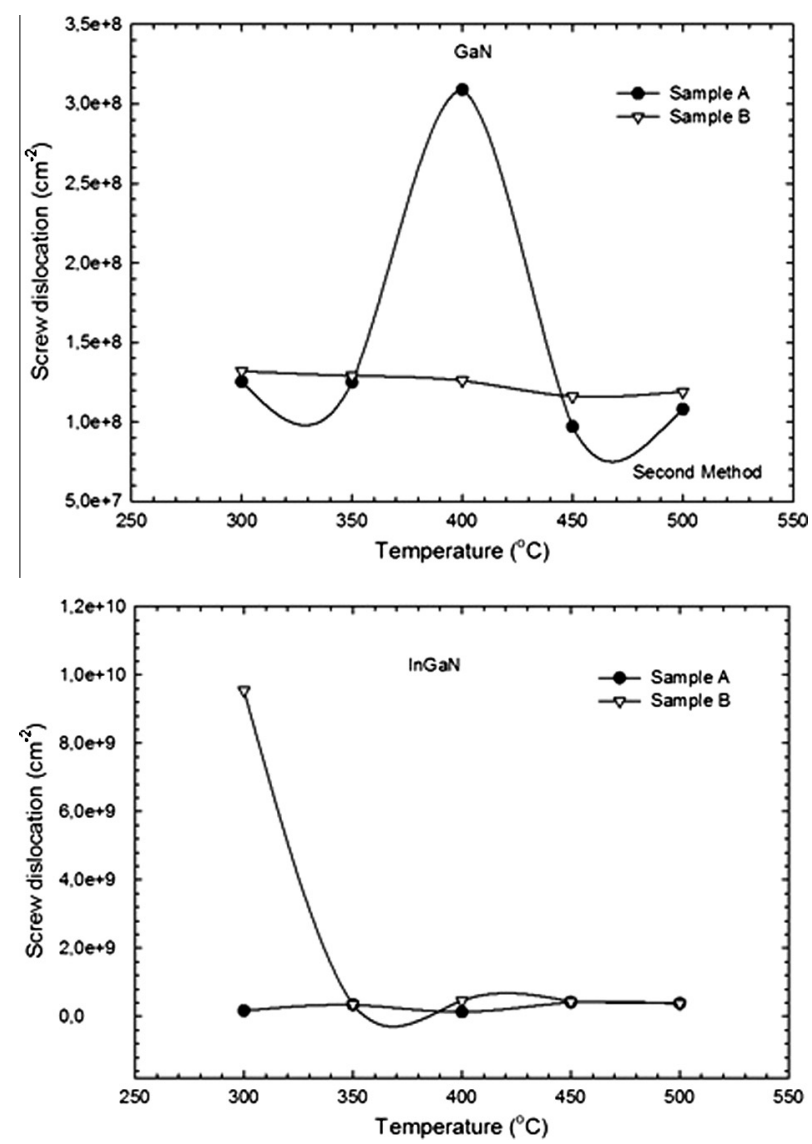

Fig. 11. Temperature dependant screw type dislocation density (a) GaN, (b) InGaN.
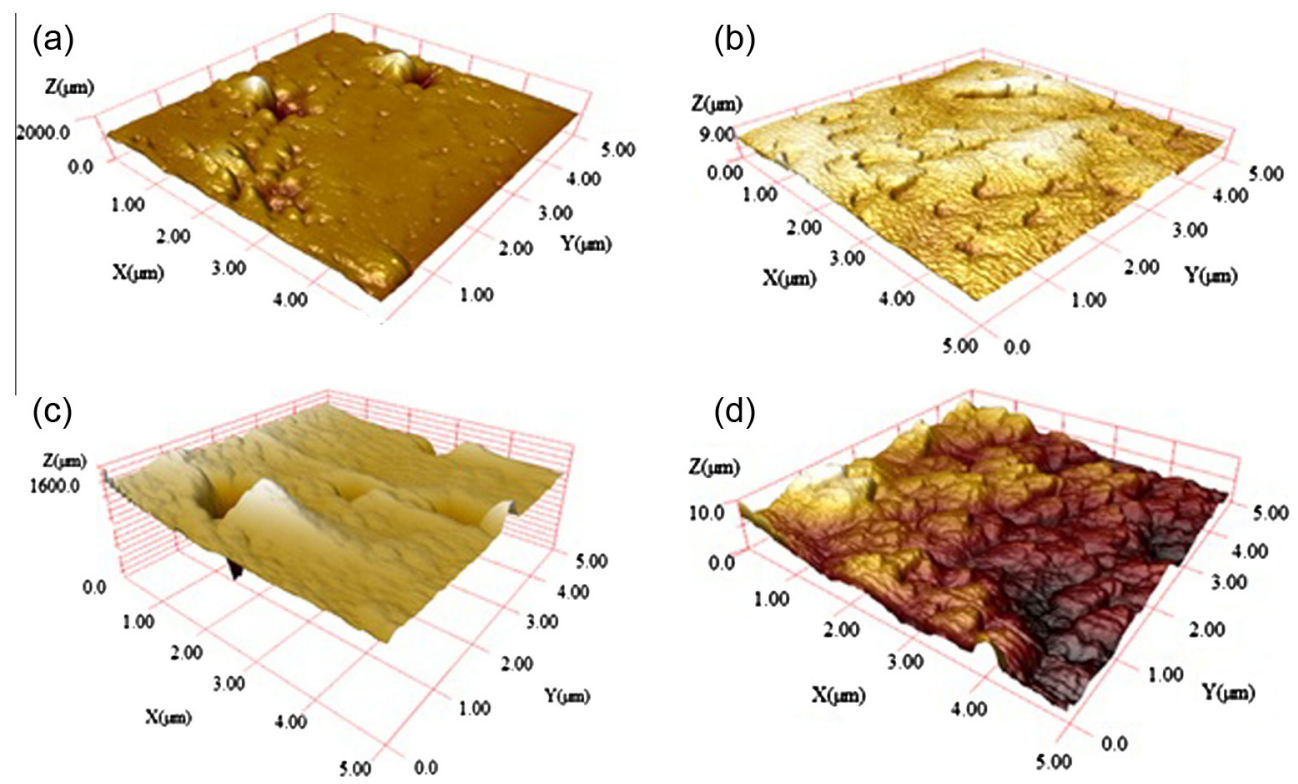

Fig. 12. AFM images after thermal annealing (a) sample $A$ at $300{ }^{\circ} \mathrm{C}$, (b) sample $A$ at $500^{\circ} \mathrm{C}$, (c) sample $B$ at $300^{\circ} \mathrm{C}$, (d) sample $B$ at $500{ }^{\circ} \mathrm{C}$. 


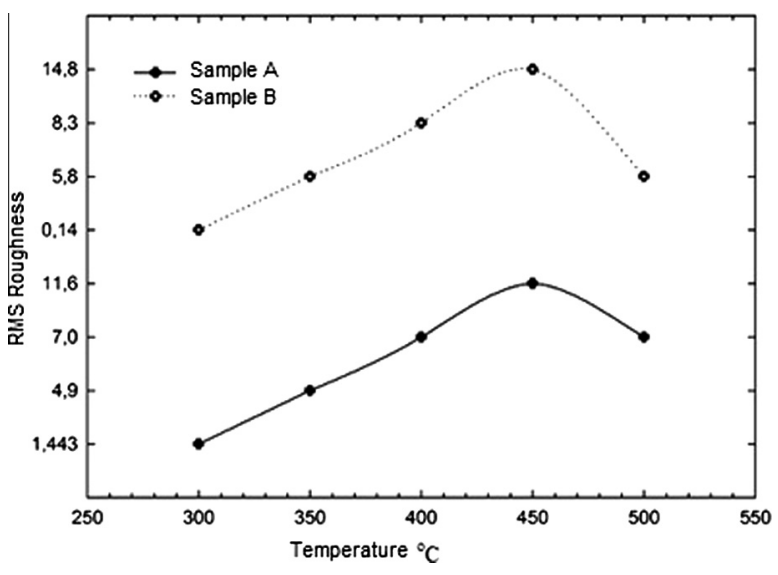

Fig. 13. Temperature dependant surface roughness of sample A and B.

structure is observed on the surface of sample A after being annealed at $500{ }^{\circ} \mathrm{C}$. The surface RMS roughnesses of the samples are indicated in Fig. 13. While the surface roughnesses of the In graded sample A progressed at a lower level, sample B showed the same behavior trend due to the fact that the growth conditions of both samples were the same.

\section{Conclusion}

In this study are $\operatorname{In}_{x} \mathrm{Ga}_{1-x} \mathrm{~N}$ samples grown on $c$-oriented sapphire substrate by the MOCVD technique. The effect of different growing conditions on the quality of the samples is examined.

First, the graded and ungraded grown A and B samples are annealed in $50{ }^{\circ} \mathrm{C}$ steps between $300{ }^{\circ} \mathrm{C}$ and $500{ }^{\circ} \mathrm{C}$. The structural properties of samples A and B are determined by the High Resolution X-ray Diffraction. The peak maximum of the symmetric HRXRD omega peaks, half-widths (FWHMs) for the GaN and InGaN layers are compared. It is stated that the FWHM values rose by the increasing alloy compound, that the thermodynamic stability of $\operatorname{In}_{x} \mathrm{Ga}_{1-x} \mathrm{~N}$ decreased along with the increasing $x$, and that the structure became more strained.

The temperature dependant Williamson-Hall graphics are drawn for GaN and InGaN and the mosaic crystal failures are calculated by these graphics. There is no general characteristic trend observed at both structures related to temperature as a result of the annealing. There are fluctuating failures determined at both structures as of $350^{\circ} \mathrm{C}$. The GaN and InGaN layer tilt angles, lateral and vertical mosaic structures and strain showed dramatic changes after $400{ }^{\circ} \mathrm{C}$. The growth temperature of $\mathrm{GaN}$ at high pressure is about $400{ }^{\circ} \mathrm{C}$. Therefore, the failures of the GaN layer increased starting from $350{ }^{\circ} \mathrm{C}$ and after $400{ }^{\circ} \mathrm{C}$. These failures in the same manner reflected on the InGaN layer. The changes to the tilt angle can be given as a sample for this situation. Both deterioration of the structure and stable situations occured along with the increasing annealing temperature. Edge type dislocations can be given as a sample for this situation.

The surface properties of the films are examined with AFM. There are significant changes developed in the topographies of the surface structures of the films after the thermal annealing process. The surface of both samples have presented a low RMS roughness after being annealed at $300^{\circ} \mathrm{C}$, and rather high RMS roughnesses depending on the annealing temperature after being annealed at higher temperature $\left(350^{\circ} \mathrm{C}\right.$ and $\left.400^{\circ} \mathrm{C}\right)$. An observation of the typical terrace structure on III-nitride surfaces resembles the surface structure on the surface of sample $A$ and a structure consisting of pits and hillocks is observed at sample B after being annealed at $500^{\circ} \mathrm{C}$.

\section{Acknowledgments}

This work is supported by the projects DPTHAMIT, DPT-FOTON, NATO-SET-193 and TUBITAK under Project Nos. 113E331, 109A015 and 109E301.

\section{References}

[1] A.G. Bhuiyan, K. Sugita, A. Hashimoto, A. Yamamoto, InGaN solar cells: present state of the art and important challenges, IEEE J. Photovoltaics 2 (3) (2012) 276-293.

[2] O. Jani, C. Honsberg, A. Asghar, D. Nicol, I. Ferguson, A. Doolittle, S. Kurtz, Characterization and analysis of InGaN photovoltaic devices, in: Proc. 31st IEEE Photovolt. Spec. Conf., Lake Buena Vista, FL, Jan. 3(7), 2005, pp. 37-42.

[3] M.A. Green, K. Emery, Y. Hishikawa, W. Warta, E.D. Dunlop, Solar cell efficiency tables, Prog. Photovoltaics Res. Appl. 19 (5) (2011) $565-572$.

[4] S.C. Jain, M. Willander, J. Narayan, R. Van Overstraeten, III-nitrides: growth, characterization, and properties, J. Appl. Phys. 87 (2000) 965.

[5] G.F. Brown, J.W. Ager, W. Walukiewicz, J. Wu, Numerical simulations of novel InGaN solar cells, in: Photovoltaic Specialists Conference (PVSC) 34th IEEE, 2009, pp. 001958-001962. 
[6] T. Yamaguchi, C. Morioka, K. Mizuo, M. Hori, T. Araki, Y. Nanishi, A. Suzuki, Growth of InN and InGaN on Si substrate for solar cell applications, in: Compound Semiconductors: Post-Conference Proceedings, International Symposium, 2003, pp. 214.

[7] Y. Nanishi, Y. Saito, T. Yamaguchi, RF molecular beam epitaxy growth and properties of InN and related alloys, Jpn. J. Appl. Phys. 42 (1) (2003) 25492559.

[8] T. Lu, C. Kao, H. Kuo, G. Huang, S. Wang, CW lasing of current injection blue GaN-based vertical cavity surface emitting lase, Appl. Phys. Lett. 92 (2008) 141102.

[9] High-Brightness LED Market Review and Forecast 2007, Published: Strategies Unlimited, 2007.

[10] J.H. Ryou, W. Lee, J. Limb, D. Yoo, J.P. Liu, R.D. Dupuis, Z.H. Wu, A.M. Fischer, F.A. Ponce, Appl. Phys. Lett. 92 (10) (2008) 101113.

[11] A. Yıldız, M.K. Öztürk, M. Bosi, S. Özcelik, M. Kasap, Chin. Phys. B 18 (2009) 4007.

[12] S. Korcak, M.K. Öztürk, S. Çörekçi, B. Akaoğlu, H. Yu, M. Çakmak, S. Sağlam, S. Özçelik, E. Özbay, Structural and optical properties of an In Ga $_{1-x}$ N/GaN nanostructure, Surf. Sci. 601 (1) (2007) 3892-3897.

[13] J.B. Whitlock, K. Morgan, S.B. Schujman, B. Raghothamachar, M. Dudley, K.R. Evans, Fabrication of native, single-crystal AlN substrates, Phys. Status Solidi C: Conferences Crit. Rev. (7) (2003) 1997-2000.

[14] J. Newey, Essient photonics brings new thinking to optical modulation technology, Compound Semicond. 8 (6) (2002) $33-37$.

[15] R. Chierchia, T. Bottcher, H. Heinke, S. Einfeldt, S. Figge, D. Hommel, Microstructure of heteroepitaxial GaN revealed by X-ray diffraction, J. Appl. Phys. $93(11)(2003) 8918$

[16] M.E. Vickers, M.J. Kappers, R. Datta, C. McAleese, T.M. Smeeton, F.D.G. Rayment, C.J. Humpreys, In-plane imperfections in GaN studied by X-ray diffraction, J. Phys. D: Appl. Phys. 38 (10A) (2005) 99-104.

[17] S.Y. Chiu, A.F.M. Anwar, S. Wu, Base transit time in abrupt GaN/InGaN/GaN HBT's, IEEE Trans. Electron Dev. 47 (4) (2000) 662-666.

[18] A. Dussaigne, B. Damilano, N. Grandjean, J. Massies, In surface segregation in InGaN/GaN quantum wells, J. Cryst. Growth 251 (1-4) (2003) 471-475.

[19] E. Arslan, M.K. Öztürk, A. Teke, S. Özçelik, E. Özbay, Buffer optimization for crack-free GaN epitaxial layers grown on Si(111) substrate by MocVD, J. Phys. D: Appl. Phys. 41 (15) (2008) 155317-155326.

[20] O. Ambacher, Growth and applications of group III-nitrides, J. Phys. D: Appl. Phys. 31 (20) (1998) 2653-2710.

[21] S. Yoshida, S. Misawa, S. Gonda, Improvements on the electrical and luminescent properties of reactive molecular beam epitaxially grown GaN films by using AlN-coated sapphire substrates, Appl. Phys. Lett. 42 (8) (1983) 427-429.

[22] Y. Baş, P. Demirel, N. Akın, C. Başköse, Y. Özen, B. Kınacı, M.K. Öztürk, S. Özçelik, E. Özbay, Microstructural defect properties of InGaN/GaN blue light emitting diode structures, J. Mater. Sci.: Mater. Electron. 25 (9) (2014) 3924-3932.

[23] T. Metzger, R. Höpler, E. Born, O. Ambacher, M. Stutzmann, R. Stömmer, M. Schuster, H. Gobe, S. Christiansen, M. Albrecht, H.P. Strun, Defect structure of epitaxial GaN films determined by transmission electron microscopy and triple-axis X-ray diffractometry, Philos. Mag. A 77 (4) (1998) 1013-1025.

[24] G.K. Williamson, W.H. Hall, X-ray line broadening from filed aluminium and wolfram, Acta Metall. 1 (1) (1953) $22-31$.

[25] H. Yu, M.K. Öztürk, S. Özçelik, E. Özbay, A study of semi-insulating GaN grown on AlN buffer/sapphire substrate by metalorganic chemical vapor deposition, J. Cryst. Growth 293 (2) (2006) 273-277.

[26] M.K. Öztürk, S. Çörekçi, M. Tamer, S.Ş. Çetin, S. Özçelik, E. Özbay, Microstructural properties of InGaN/GaN light-emitting diode structures with different In content grown by MOCVD, Appl. Phys. A-Mater. Sci. Process. 114 (4) (2014) 1215-1221. 